three months of such symptoms, associated with slight feelings of chill, a herpetic eruption appeared, ushered in quietly, and without pain or much itching. The vesicles appeared in a thickly-set patch under each eye, extending to the external canthus and internally well up the bridge of the nose on each side; round the palpebral margins, amongst the cilia, and thickly set on each eyebrow; several on each frontal region; several vesicles belind each ear; three on the right helix and over the upper lip ; one on the nose over the bridge, and one on the right side of the tip of the nose. There was soon associated with the specific eruption considerable cutaneous disturbance, with swelling of the eyelids to absolute closure. The eruption was characterised by the usual multiformity of the herpetic lesion-here vesicular, there bullous, and again pustular; all present simultaneously. The eruption under the lower lids and on the eyebrows broke down on the third day with the formation of foul ulcers discharging freely. These had fairly cleared by the fifth or sixth day, exposing corium papillæ. Throughout the attack no ocular symptoms of any gravity appeared. The conjunctivæ became suffused slightly. Vision and tension and sensation of the eyeballs remained normal throughout the attack. This lasted in all about three weeks, the only traces of its presence afterwards being a rugged scaly state of the cuticle under each eye. During the attack the patient's condition underwent very little change. In the succeeding week, however, uncontrollable hiccough, with rigors, occurring nightly, set in, the temperature rising from $102^{\circ}$ to $103^{\circ}$. The albumen in the urine in creased in quantity, being 35 oz; sp. gr. 1010 ; granular casts. Shortly afterwards vomiting became a constant symptom, and shortly terminated the case.

Remarks.-The post-mortem examination generally bore out the diagnosis which heads the article, and was conducted by Dr. Drummond of Newcastle, who kindly saw the case with me once or twice during its progress. As to the eruption, the clustering together of the vesicles into groups, and its appearance on other parts in the course of the nerve distribution, all so characteristic of herpes, established the diagnosis at the onset. Subsequently viewing the lesions when the vesicles became confluent, purulent, and broken down, leaving large freely discharging ulcers under the eyes and on the upper orbital boundaries, a lifferent opinion might have been formed. This, with the extreme swelling of the lids, presented a close resemblance to erysipelas. The striking features of course were the bilateral occurrence of the eruption and the absence of any serious ocular sympathy in the process from first to last. Mr. Hutchinson states that the severity of the disease is in proportion to that with which the tip of the nose was affected; and if the disease occurred in the latter situation the eye suffered. It will have been observed from the above account that the ophthalmic nerve in all its terminal branches was affected-viz., the lacrymal, the frontal (supra-trochlear), and the oculo-nasal ; of the superior maxillary nerve, the inferior palpebral, the lateral nasal, and the superior labial branches were affected; and of the inferior maxillary nerve the auriculo-temporal suffered in its branches behind the ear. As previously stated, the eyeball remained perfectly normal throughout, during the weeks the patient survived, after the attack of herpes had entirely disappeared. At no timewas vision at fault; the cornex remained perfectly clear, with normal tension of globes.

Neweastle-on-Tyne.

The Mothers' Lying-IN Home, Shadwell.This institution, established about four years ago by Mrs. Ashton Warner, recently held its annual meeting of oovernors. The Earl of Meath presided. Since the opening of the Home, 405 patients had been registered, and 327 admitted and discharged well. During the past year, 103 mothers were treated with satisfactory results. The expenditure amounted to $\$ 810 \quad 11 s$. $2 d$. The present limited accommodation was represented as quite inadequate to meet the increasing demands upon the Home, and necessitated its periodical closing at intervals for sanitary requirements.

Polltion of the Thames. - The Chertsey Rural Sanitary Authority were on Wednesday, at the Petty Sessions, fined $t 50$ and ten guineas costs for suffering pollnted matter to flow in to a tributary of the River Thames at Chertsey, and $f 5$ in respect of a similar offence committed at Addlestone.

\section{olintal alotes:}

\section{MEDICAL， SURGICAL，OBSTETRICAL，AND THERAPEUTICAL.}

\section{REMOVAL OF THREE INTRA-UTERINE FIBROIDS BY ENUCLEATION.}

By D. MacGregor, M.A., M.D. EdiN.

AN urgent summons to attend Mrs. $R$ - reached me on March 30th of this year. Flooding had suddenly become alarming, and the patient fainted: She is aged forty-seven, the wife of a farm servant, and the mother of six children, four of whom are adults. She is a thin, anxmic-looking woman. For the past two years menstruation had been irregular, occurring on an average once in three months. At these periods she lost much blood and suffered pain. During the two years she had also had difficulty and pain in both defecation and micturition : bowels constipated; micturition frequent. The patient attributed these symptoms to "change of life." Family history unimportant.

I found the patient in bed, blanched and weak. On abdominal palpation there was found a central tumour reaching from the pubes to the umbilicus; the tumour was only slightly painful to the tonch, and appeared to be uterine. The abdominal superficial veins were distended. On examination per vaginam, there was felt a smooth globular tumour, large enough to fill the hollow of a hand. The os uteri was widely dilated, and the tumour protruded into the vaginal canal. The tumour was sessile, and was continuous with the posterior lip of the cervix and with the posterior uterine wall. The attachment was extensive. The uterine sound entered the uterus to the extent of six inches and a half; and there seemed to be an impediment, overcome only by some manœuvring after the sound had entered two inches. Ergot, nux vomica, iron, and opium were administered, the vagina was plugged, absolute rest enjoined, and the patient given the most nutritious diet. As soon as the plug was removed hamorrhage recurred. It was evident that an operation was the only safe course; and the method of enucleation was adopted on the suggestion of my friend Dr. Mitchell Penman, who saw the patient with me.

On April 26th, Dr. Penman having administered chloroform, and the patient having been put in the lithotomy position opposite the only window in the room (in patient's own house), I seized and drew down the tumour with a vulsellum, slit the capsule, and proceeded to enucleate. The process of enucleation was found tiresome to the finger, and we found it convenient to relieve each other; after enucleating as far as possible, separation of the tumour was effected by arulsion. After the first tumour was removed another appeared, and after the removal of this a third presented itself. The three tumours having been removed, the capsule treated, and the uterus washed out, the patient was removed to bed. There was no hremorrhage. The time that elapsed from the moment the patient was placed on the operating table until she was again in bed was forty-five minutes. On the evening of operation the temperature was $103^{\circ} \mathrm{F}$., and the pulse 100 ; and a sharp attack of bronchitis, to which the patient is subject, kept the temperature somewhat above normal for the first eight or nine days. On the subsidence of the bronchitic attack the patient made rapid progress. She now (May 20th) takes open-air exercise on foot daily, and feels in every respect well. The three tumours together weighed twenty-eight ounces; the measurements, in order of their presentation, were six inches by three, seven and a half inches by four, and six inches by three and a half.

Denholm, Hawick, N.B.

\section{NOTES ON A}

\section{CASE OF POISONING BY HYDROCYANIC ACID.}

\section{BY E. M. Garstang, M.R.C.S., L.R.C.P. Edin.}

ON July 29th, 1887, I was ealled in haste to Miss B-, fifty-eight vears of age, who was reported to have been suddenly seized with apoplexy. I saw her about $9.25 \mathrm{~A} . \mathrm{M}$., and found her perfectly insensible; breathing stertorous and irregular; severe twitchings of face; eyes directed 
upwards and towards the right side; slight opisthotonos and tonic spasm of both arms and legs; very slight frothing at mouth; jaws firmly clenched; heart's action slow, laboured, and irregular; pulse imperceptible at wrist; extremities cold and bathed with clammy perspiration. Mustard and hot water fomentations were applied to the legs and thighs, and hot sinapisms over the leart. On inquiring as to what the patient had taken, I was informed that she had had a cup of tea and also a dose of medicine, which had been dispensed on the previous day by a chemist. On smelling the bottle a strong odour of bitter almonds was clearly perceptible. I then asked for the prescription, which I found was as follows:- " R Pot. bicarb., 3 iv.; acid. hydrochl. dil., $z i_{\text {. }}$; aquæ ad 5 viii. Allow the effervescence to subside before placing in the bottle. Cap. 3 ss. ter in die." However, by an unfortunate mistake hydrocyanic acid had been used instead of the dilute hydrochloric acid. The patient took one dose of the medicine, which would be equal to half a drachm of the B.P. acid, and died one hour and twenty minutes from the time of taking the dose, and about half an hour after my arrival.

Necropsy, eight hours after death.-Body well nourished; no external marks beyond those of already commencing decomposition (the day being unusually hot). Heart somewhat fatty and its muscular tissue friable; odour of almonds distinctly perceptible on opening the pericardium, which contained about an ounce and a half of fluid. Left ventricle found firmly contracted and empty; right ventricle somewhat thin and relaxed, containing about an ounce of dark-coloured fluid blood. The lungs were somewhat congested, and adherent in places to the chest wall; also slightly emphysematous. Liver somewhat congested ; friable. Kidneys and spleen healthy. All the viscera of both chest and abdomen were characterised by the peculiar odour of bitter almonds. The membranes of the brain were found considerably engorged, as also the sinuses. But in the brain tissue the puncta were almost imperceptible owing to the anæmic character of the brain substance itself. The cerebro-spinal fluid and brain tissue gave off the characteristic smell. About two ounces of yellowish semitransparent fluid were contained in the stomach; this was afterwards submitted to analysis, and found to give slight but unmistakable evidence of the presence of the prussic acid.

This case appears to me to be interesting, first, on account of the smallness of the dose, which was followed within about five minutes by complete insensibility, owing doubtless to the rapidity with which the poison became absorbed, the stomach being almost empty at the time of taking the fatal dose; and, secondly, that, the dose being so small, it should afford such conclusive and unmistakable signs of its presence in all the tissues.

Haulgh, Bolton.

\section{A FOREIGN BODY IN THE EAR FOR EIGHTEEN YEARS.}

By Alfred Swann, M.D., M.R.C.S.,

SURGEON TO THE BATLEY AND DISTRICT COTTAGE MOSPITAL.

THE following case came under my care recently, and may be deemed interesting.

G. I- aged twenty-seven, consulted me in May, complaining of irritability of the fauces, particularly on the right side, and deafness on the same side. He said that eighteen years ago, when a child, he was playing with a piece of slate pencil, and poked it into his ear. He went to a medical man, who attempted to remove the body, but did not succeed. Deafness gradually supervened, and unless some conducting medium was used the man could not detect sounds at all. On examining the ear with a speculum, it was found to contain cerumen, but nothing else could be seen. A few syringefuls of warm water and carbonate of soda soon dislodged a long plug of what appeared to be cerumen, but embedded in this was a piece of slate pencil half an inch long, with its rounded end towards the drum of the ear. Hearing was immediately and perfectly restored, and on examination the tympanum was found to be perfectly whole and healthy. The throat symptoms cleared up in the course of a few days.

This case seems to be interesting as showing the toleration which the auditory canal may have for foreign bodies, and also on account of the sympathetic irritation of the throat.

Batley, Yorkshire

\section{A FORM OF UMBILICAL SINUS OCCURRING IN} ADULTS.

By Alex. G. R. Foulerton, M.R.C.S., L.R.C.P.

THE form of umbilical sinus to which I would draw attention, although doubtless frequently met with in practice, has not, I believe, been generally recognised in surgical works. Umbilical fistulæ of greater or less extent depending upon non-coalescence of the urachus or omphalomesenteric duct are described. So also a fistula leading down to an abscess cavity within the abdomen, usually seen in children and often in connexion with diseased mesenteric glands. Biliary and fæcal fistulæ may in like manner find their point of discharge at the same spot. The sinus now under consideration, however, does not extend deeper than the abdominal walls; it is merely the normal umbilical depression converted into a suppurating cavity. Its chief clinical characteristic has been a marked obduracy to treatment, depending probably on the fact that its exact pathology has not been understood. The cause of the irritation in four cases of this complaint, all occurring in women, which have come under my notice has been the same-viz., retained sebaceous matter. The presence of a hard plug of mingled dirt and sebaceous matter can frequently be demonstrated in the umbilicus, especially in persons who give not due regard to personal cleanliness. It will vary in size from a hemispherical mass the size of a small split-pea, lying deep down in the umbilicus, to a larger concretion filling the whole depression, and presenting itself as a black disc, its upper surface being flush with the surrounding skin. This being so, it is easy to conceive that such a plug may set up considerable irritation, and the suppuration so induced is likely to contirue until the cause has been removed. Bearing this in mind, the treatment is simple. The cavity should first be thoroughly scraped out, particular attention being paid to the deeper parts; the application of nitric acid will then ensure a healthy granulating surface. For the scraping, a most convenient scoop may be extemporised by inverting a pen-nib in its holder. The cases thus treated have all healed rapidly after having already resisted various other methods. In one of the cases, after application of nitric acid the sinus still refused to heal. It was then found that what had been mistaken for a large granulation at the bottom of the sinus was in reality an encapsuled mass of sebaceous matter, presumably an obstructed follicle. On this being turned out, the whole thing was well within a week. There is yet another form of umbilical sinus caused by the spreading downwards of eczema, but as to the treatment of this $I$ have no experience.

St. Bartholomew's Hospital, Chatham.

\section{SYMPTOMS OF POISONING BY ETHUSA CYNA PIULI (FOOL'S PARSLEY).}

BY E. SCOTT SUGDEN, M.B.,

SENIOR HOUSE SURGEON, BIRKENHEAD BOROUGH HOSPITAL.

JoSEPH P_ aged nineteen, applied at the Birkenhead Borough Hospital at 8.30 A.M. on June 29th. He stated that on the previous evening he gathered by the hedgeside several leaves of a herb he thought to be tansy. Before going to bed he ate a few of these leaves, and about 3 o'clock in the morning he began to vomit ; this vomiting continued for three or four hours off and on till he came to the hospital. When I saw him at $8.30 \mathrm{~A}$.M. he complained of nausea and headache, with a burning sensation about the month and throat. The pupils were widely dilated, and the pulse very quick and feeble. The patient was put to bed, and no treatment ordered beyond a five-grain calomel powder and an ounce of castor oil. By the next morning he was quite well. The lad brought with him a piece of the herb, which was undoubtedly fool's parsley, and the case is interesting in view of the experiments made some years ago by Dr. John Harley (St. Thomas's Hospital), which were supposed to prove that the herb was completely harmless.

\section{Birkenhead.}

Great Northern Central Hospital. - The Prince and Princess of Wales have now arranged to open the new buildings on Tuesday, July 17th, at 4.30 P.M. 